\title{
BMJ Open The independent associations of recorded crime and perceived safety with physical health in a nationally representative cross-sectional survey of men and women in New Zealand
}

\author{
Gina S Lovasi, ${ }^{1}$ Charlene E Goh, ${ }^{1}$ Amber L Pearson, ${ }^{2}$ Gregory Breetzke ${ }^{3}$
}

To cite: Lovasi GS, Goh CE, Pearson AL, et al. The independent associations of recorded crime and perceived safety with physical health in a nationally representative cross-sectional survey of men and women in New Zealand. BMJ Open 2014;4: e004058. doi:10.1136/ bmjopen-2013-004058

- Prepublication history for this paper is available online. To view these files please visit the journal online (http://dx.doi.org/10.1136/ bmjopen-2013-004058).

Received 17 September 2013 Revised 17 January 2014 Accepted 14 February 2014

\section{CrossMark}

${ }^{1}$ Department of Epidemiology, Columbia University, Mailman School of Public Health, New York, New York, USA

${ }^{2}$ Department of Public Health, University of Otago, Wellington, New Zealand ${ }^{3}$ Department of Geography, University of South Africa, Pretoria, South Africa

Correspondence to Dr Gina S Lovasi; glovasi@columbia.edu

\section{ABSTRACT}

Objectives: We investigated associations of officially recorded crime and perceived neighbourhood safety with physical health, evaluating potential effect modification by gender.

Setting: Nationally representative population-based survey in New Zealand.

Participants: Individual-level data from 6995 New Zealand General Social Survey (2010-2011) participants with complete data on physical health status, perceived neighbourhood safety, sociodemographic characteristics and smoking. Crime rate for each participant's home census was estimated based on data from the New Zealand Police (2008-2010).

Primary outcome measure: The Transformed Physical Composite Score from the SF-12, a physical health summary score based on self-report ranging from 0 to 100 . Results: We used cluster robust multivariable regression models to examine the associations among neighbourhood crime rates, perceived neighbourhood safety and the physical health summary score. Crime rates predicted adults' perception that it was unsafe to walk in their neighbourhood at night: for each additional crime per 100000 residents adults were $1.9 \%$ more likely to perceive their neighbourhood as unsafe $(95 \% \mathrm{Cl} 1.2 \%$ to $2.5 \%$ ). While relatively uncommon, the rate of crime with a weapon strongly predicted perceived safety: for each additional crime per 100000 residents in this category, adults were $12.9 \%$ more likely to report the neighbourhood as unsafe (95\% $\mathrm{Cl} 8.8 \%$ to $17.0 \%)$. Police-recorded violent and night crime rates were associated with worse physical health among women: for each additional crime per 100000 residents in these category women had a 0.3 point lower physical health score $(95 \%$ Cls -0.6 to -0.1 for violent crime and -0.5 to -0.1 for crime at night, gender interaction p values 0.08 and 0.01 , respectively). Perceiving the neighbourhood as unsafe was independently associated with 1.0 point lower physical health score $(95 \% \mathrm{Cl}-1.5$ to -0.5$)$.

Conclusions: Gender may modify the associations of officially recorded crime rates with physical health. Perceived neighbourhood safety was independently associated with physical health.

\section{Strengths and limitations of this study}

- Use of geographically linked national data.

- Multiple officially recorded crime rates by category using 3 years of data to obtain more stable rates.

- Survey question on perceived neighbourhood safety.

- SF-12 instrument used for outcome assessment has been validated and recommended as a population health measure.

- Power to test for interaction by gender on the association between neighbourhood crime and health.

- Cross-sectional and observational study designs limit our ability to eliminate non-causal explanations.

- Physical health status was self-reported, which could result in misclassification.

- Missing data may lead to a biased estimate of the associations between crime rates, perceived safety and health status.

- Misclassification or reasons for missing data could differ by gender, potentially distorting the observed pattern of effect modification.

- Measure of perceived safety did not explicitly state the source for concern with safety and some participants may be considering factors such as traffic hazards instead of crime.

- Lower crime rates and other unique sociocultural factors may change how New Zealand neighbourhoods function and influence health, limiting generalisability.

\section{INTRODUCTION}

Neighbourhood characteristics have previously been shown to influence health. ${ }^{1-3}$ Crime is one such neighbourhood characteristic. Residents living in areas with higher crime rate have been shown to have worse physical health, ${ }^{4-6}$ even after controlling for the potential confounding effect of 
sociodemographic characteristics. There are several causal pathways by which local crime rates can affect health, including trauma resulting from victimisation or chronic stress $^{7}$ and anxiety related to a perceived threat. ${ }^{8}$ Stress pathways could involve mental health, sleep duration or stress-coping behaviours such as tobacco use or alcohol intake. Other behavioural pathways could also play a role if outdoor physical activities, such as walking in the neighbourhood, were restricted to minimise victimisation risk, adversely affecting physical health. ${ }^{9}{ }^{10}$ Thus, potential health benefits may be among the reasons to pursue local crime prevention.

Although recorded crime may be thought to influence health status through perceived safety, the role of perceived safety as a mediator of this relationship has often been assumed rather than tested empirically. ${ }^{11}$ Independent or divergent associations have been observed for officially recorded crime as compared with perceived safety problems in analyses predicting health and health behaviours, suggesting that recorded crime and perceived safety may not be simply serving as proxies for each other. ${ }^{11}{ }^{13-18}$ In addition to officially recorded crime, the perception of safety may be influenced by environmental- and neighbourhood-level factors, such as social cohesion, street lighting and neighbourhood physical disorder. ${ }^{9}{ }^{10}$ A recent systematic review highlighted many inconsistencies in the literature on the link between officially recorded crime and perceived safety with physical activity. ${ }^{10}$ Yet, individual perceptions and responses to the local environment may not be the same for all groups. ${ }^{16}$ Associations of local crime rates with health have been shown to vary based on local ${ }^{17}$ or national socioeconomic context, ${ }^{18}$ as well as by gender. ${ }^{10} 121418-20$

Men and women have been shown to differ in their perceived risk of victimisation and fear depending on the type of crime $^{21}$; they have also been observed to vary in their likelihood of exercise associated with perceived safety. ${ }^{20}$ It has also been suggested that women might be more exposed to their local area than men, ${ }^{22}$ which may contribute to the differences in associations with officially recorded crime and self-reported perception of safety on health.

This study sought to assess the association of officially recorded crime and self-reported perception of safety on physical health status in a national sample of adult New Zealanders using data from the New Zealand General Social Survey (NZGSS) and crime data obtained from the New Zealand Police. We hypothesised that recorded crime would be negatively associated with physical health, and that the perception of a neighbourhood as being 'unsafe' would both partially mediate the relationship between recorded crime and physical health, as well as independently predict worse physical health after controlling for recorded crime in the neighbourhood of residence. Distinguishable subsets of officially recorded crime rates (by crime type, time of occurrence, involvement of a weapon) allow us to investigate the categories of crime that are most associated with perceiving a neighbourhood as unsafe and with experiencing worse physical health. We explored whether these associations differed by gender, as men and women may differ in their perception of neighbourhood problems, or their stress and behavioural responses to perceived safety hazards.

\section{MATERIALS AND METHODS}

\section{Study design and population}

The NZGSS was designed to provide information on the well-being of New Zealanders. The NZGSS is a nationally representative cross-sectional survey of New Zealand residents aged 15 years and over. Detailed information on sampling and methodology of the NZGSS has been previously published. ${ }^{23}$

Briefly, the survey employed a multistage sample, and a total of 8550 participants answered the NZGSS personal questionnaire during a 12-month period from April 2010 to March 2011 (81\% response rate). The NZGSS was interviewer administered in person using computer-assisted personal interviews which covered a wide range of social and economic topics, including sociodemographic characteristics, perceived neighbourhood safety and self-reported health.

\section{Physical health status outcome based on self-report}

The outcome variable of interest-physical health status - was self-assessed and measured in the NZGSS by the commonly used SF-12 Health Index, a short version of the SF-36. ${ }^{24}$ The SF-12 consists of 12 questions, covering aspects of physical and mental health. ${ }^{25}$ Example questions: "In general, would you say your health is excellent, very good, good, fair or poor?", "During the past four weeks, how much of the time were you limited in the kind of work or other regular daily activities you do as a result of your physical health?" Responses were weighted and combined into a physical health summary score, the Transformed Physical Composite Score (TPCS) ranging from 0 to $100 .^{26}$

\section{Officially recorded crime rates}

Data of officially recorded crime throughout New Zealand for the period (2008-2010) were obtained from the New Zealand Police. Crime rates from 2008 to 2010 were selected for their temporal correspondence with the data collection in $2010-2011,{ }^{27}$ characterising a period largely preceding our outcome measurement and using 3 years of data to obtain more stable rates. The data included over 360000 incidents of crime recorded nationally, which have been geocoded and aggregated from the meshblock level to the census area unit (CAU). Each CAU contains approximately 2000 people. Crime data were categorised by type (violent, property, dishonesty or drug and antisocial), whether a weapon was involved, and whether the offence occurred at night (defined as between 20:00 and 7:59). For 
overall crime and each category, the average count over the 3-year period was combined with CAU population data to create average annual rates per 100000 population (see table 1). Crime rates were then linked to individual-data from the NZGSS based on the CAU corresponding to the residential address provided at the time of the NZGSS survey.

\section{Perceptions of neighbourhood as unsafe at night}

Perceptions of the neighbourhood as being 'unsafe' at night was assessed by asking NZGSS participants: "How safe do you feel walking alone at night in your neighbourhood?" Potential answers ranged on a Likert-type 4-point scale from 1 'very safe' to 4 'very unsafe'. Responses were dichotomised such that feeling 'unsafe/ very unsafe' was considered as representing a perceived safety problem for analyses. Similar measures have been used in previous studies either as an individual measure or as part of a composite scale. ${ }^{12} 28-30$

\section{Individual sociodemographic characteristics and smoking}

Age group (age 15-24, 25-44, 45-64 and 65+years), gender, ethnicity (Māori, the indigenous population of New Zealand (1) vs Non-Māori (0)), individual-level socioeconomic status (SES), country of birth and smoking status (never, former and current) were considered as physical health determinants that are also potentially associated with place of residence but not on the causal pathway, and thus as potential confounders. SES is a wellknown confounder of the relationship between neighbourhood characteristics and health ${ }^{3}$; available SES measures included education (none or national certificate 1-4, diploma or bachelors or masters or doctorate), employment (currently working for pay (1) vs otherwise (0)), and income (\$NZ0-\$NZ20 000, \$NZ20 001-\$NZ40 000, $\$ N Z 40001-\$ N Z 60000,>\$ N Z 60000$ per year). Being foreign-born has been found to be associated with neighbourhood of residence and physical health status. ${ }^{31}$ Place of birth was dichotomised into New Zealand-born (1) and born outside of New Zealand (0).

\section{Statistical analyses}

A linear probability model with cluster robust SEs was used to explore the relationships between crime rates and perception of the neighbourhood as unsafe. Cluster robust linear regression analyses were used to examine the associations between officially reported crime rates and perception of the neighbourhood as unsafe predicting physical health status. An intraclass correlation coefficient (ICC) was used to assess, and cluster robust SEs were used to account for, the potential nonindependence of physical health status scores within the same CAU. Due to the correlations between the different types of crime rates (see table 1), we assessed associations for each recorded crime rate separately and did not mutually adjust for multiple categories of crime in the same model. All models controlled for age, gender, ethnicity, place of birth, education, employment, income and smoking status.

Perception of safety was added to models with officially recorded crime rates to test for independent associations with health and to check for patterns of association consistent with mediation of the crime ratehealth associations. Mediation was expected to manifest as (1) an association between higher crime rate and lower perceived safety, (2) an association between lower perceived safety and worse health status and (3) attenuation of the crime rate-health association when perceived safety is added to the model. Furthermore, as gender was of interest as a potential effect measure modifier, gender stratification was considered for all analyses; Wald $p$ values to evaluate the statistical significance of observed effect modification were calculated from models including a gender interaction. Participants with missing values for any of the analysis variables $(\mathrm{N}=1555)$ were excluded from descriptive statistics and regression

Table 1 Correlation matrix of New Zealand Police recorded crime rates by type, weapon use and time of day across census area units inhabited by New Zealand General Social Survey participants

\begin{tabular}{|c|c|c|c|c|c|c|c|c|}
\hline Category label and definition & $\begin{array}{l}\text { Mean } \\
(\mathrm{SD})\end{array}$ & $\begin{array}{l}\text { Percentiles } \\
\text { (25th, 50th, 75th) }\end{array}$ & Total & Violent & Property & Dishonesty & Drug & Weapon \\
\hline Total crime & $2.2(2.2)$ & $(0.7,1.4,3.3)$ & - & & & & & \\
\hline $\begin{array}{l}\text { Violent crime (minor assault, serious } \\
\text { assault and grievous assault) }\end{array}$ & $1.0(1.4)$ & $(0,0.7,1.3)$ & 0.56 & - & & & & \\
\hline Property crime (burglary and theft) & $0.5(0.8)$ & $(0,0.3,0.7)$ & 0.42 & 0.64 & - & & & \\
\hline $\begin{array}{l}\text { Dishonesty crime (involving } \\
\text { destruction of property) }\end{array}$ & $0.7(1.1)$ & $(0,0.3,1.0)$ & 0.42 & 0.49 & 0.52 & - & & \\
\hline $\begin{array}{l}\text { Drug and antisocial crime (drug } \\
\text { related and disorder) }\end{array}$ & $0.6(1.2)$ & $(0,0,0.7)$ & 0.46 & 0.45 & 0.46 & 0.35 & - & \\
\hline Crime with a weapon & $0.1(0.3)$ & $(0,0,0)^{*}$ & 0.32 & 0.51 & 0.50 & 0.34 & 0.38 & - \\
\hline $\begin{array}{l}\text { Crime at night (committed between } \\
20: 00 \text { and } 7: 59 \text { ) }\end{array}$ & $1.2(1.6)$ & $(0,0.7,1.7)$ & 0.56 & 0.80 & 0.65 & 0.57 & 0.57 & 0.48 \\
\hline
\end{tabular}


analyses. Compared to the full sample, participants in our analyses were somewhat more likely to be men, young, educated or employed. All statistical analyses were carried out in a secure data lab in Wellington, New Zealand using Stata V.11.0 software (Stata Corp, College Station, Texas, USA).

\section{RESULTS}

\section{Study participants}

Table 2 shows the characteristics of the study population $(\mathrm{N}=6995)$. There were similar numbers of men $(n=3310)$ and women $(n=3685)$. Twelve per cent of the study participants were of Māori ethnicity. Most participants were New Zealand-born (77\%) and $65 \%$ of participants were currently employed. Approximately $21 \%$ of men reported feeling unsafe or very unsafe walking alone at night in their neighbourhood compared with $52 \%$ of women.

The physical health index (TPCS based on SF-12) had a theoretical range from 0 to 100 , with higher values indicating better physical health. The observed mean and SD were similar for men and women. The ICC for the physical health index across CAUs suggests that $3.1 \%$ of the outcome variation may be explained at the CAU level (95\% CI $1.7 \%$ to $4.5 \%)$.

\section{Association between officially recorded crime rates and perceived safety}

Total crime rate was significantly associated with the perception of one's neighbourhood as unsafe for walking at night (table 3). Associations were statistically significant for both genders and for all four types of crimes, except that among men the trend was not statistically significant for dishonesty crime (gender interaction $\mathrm{p}$ value $=0.03$ ) While relatively uncommon, the rate of crime with a weapon predicted perceived safety: for each additional crime per 100000 residents in this category women were $15.7 \%$ more likely to perceive their neighbourhood as unsafe and men were $10 \%$ more likely to perceive their neighbourhood as unsafe.

\section{Association between officially recorded crime and physical health status}

Total crime rate had a non-significant association with overall lower physical health among men (table 4). However, among women, the total crime rate, violent crime rate, and crime at night were significantly

Table 2 Characteristics of New Zealand General Social Survey participants in our analytic dataset (2010-2011, participants with missing data have been excluded)

\begin{tabular}{|c|c|c|c|}
\hline & Total $\mathrm{N}=6995$ & Men $\mathrm{N}=3310$ & Women $\mathrm{N}=3685$ \\
\hline \multicolumn{4}{|l|}{ Age group (years) } \\
\hline $15-24$ & 12 & 13 & 12 \\
\hline $25-44$ & 36 & 34 & 37 \\
\hline $45-64$ & 35 & 34 & 35 \\
\hline $65+$ & 18 & 18 & 17 \\
\hline \multicolumn{4}{|l|}{ Ethnicity } \\
\hline Māori & 12 & 10 & 13 \\
\hline \multicolumn{4}{|l|}{ Nativity } \\
\hline Born in New Zealand & 77 & 76 & 78 \\
\hline \multicolumn{4}{|l|}{ Highest completed education } \\
\hline None or national certificate $1-4$ & 66 & 70 & 63 \\
\hline Diploma or bachelors & 25 & 22 & 27 \\
\hline Masters or doctorate & 9 & 8 & 9 \\
\hline \multicolumn{4}{|l|}{ Employment } \\
\hline Currently working for pay & 65 & 70 & 60 \\
\hline \multicolumn{4}{|l|}{ Income } \\
\hline$\leq \$ N Z 20000$ & 36 & 28 & 43 \\
\hline$\$ N Z 20001-40000$ & 27 & 24 & 30 \\
\hline$\$ N Z 40001-60000$ & 18 & 21 & 15 \\
\hline$\$ N Z 60001+$ & 19 & 27 & 12 \\
\hline \multicolumn{4}{|l|}{ Smoking status } \\
\hline Regular smoker, current & 20 & 20 & 19 \\
\hline Regular smoker, former & 29 & 31 & 26 \\
\hline Never smoker & 52 & 49 & 54 \\
\hline \multicolumn{4}{|l|}{ Neighbourhood safety (self-report) } \\
\hline Safe or very safe & 63 & 79 & 48 \\
\hline Unsafe or very unsafe & 37 & 21 & 52 \\
\hline Physical health (TPCS) & $49.6(9.9)$ & $49.8(9.5)$ & $49.5(10.2)$ \\
\hline
\end{tabular}


Table 3 Associations between recorded crime rates and self-reported perception of neighbourhood as unsafe among men and women in New Zealand (2010-2011)

\begin{tabular}{|c|c|c|c|c|}
\hline & Overall $\beta$ (95\% Cl) & Men $\beta$ (95\% Cl) & Women $\beta$ (95\% Cl) & Gender interaction $p$ value \\
\hline Total crime & 1.9 (1.2 to 2.5$)$ & 1.4 (0.6 to 2.1$)$ & $2.2(1.4$ to 3.1$)$ & 0.15 \\
\hline Violent crime & 4.3 (3.1 to 5.4$)$ & 4.0 (2.6 to 0.5$)$ & 4.5 (3.0 to 5.9$)$ & 0.89 \\
\hline Property crime & 5.4 (3.4 to 7.4$)$ & 4.2 (1.9 to 6.4$)$ & 6.5 (4.1 to 9.0$)$ & 0.14 \\
\hline Dishonesty crime & 2.1 (0.6 to 3.5) & $0.7(-0.7$ to 2.2$)$ & 3.2 (1.2 to 5.2$)$ & 0.03 \\
\hline Drug and antisocial crime & 2.2 (0.9 to 3.4$)$ & $1.9(0.4$ to 3.4$)$ & 2.4 (0.8 to 3.9$)$ & 0.85 \\
\hline Crime with a weapon & $12.9(8.8$ to 17.0$)$ & $10.0(5.0$ to 15.1$)$ & 15.7 (9.9 to 21.4$)$ & 0.19 \\
\hline Crime occurring in the night & $3.0(2.0$ to 4.0$)$ & 2.7 (1.6 to 3.9$)$ & $3.2(1.9$ to 4.5$)$ & 0.80 \\
\hline
\end{tabular}

associated with a lower physical health index (coefficients were $-0.15,-0.32$ and -0.29 , respectively). This suggests that for each additional crime per 100000 residents we would expect a decrease in the physical health index of 0.15 units, or perhaps an approximately 0.3 unit decrease if the additional crime were violent or committed at night. The effect modification by gender was only statistically significant for crime at night $(\mathrm{p}=0.01)$.

To assess whether the perception of one's neighbourhood as being unsafe mediated the associations between recorded crime and physical health status, an indicator of perceived safety was added to models of recorded crime and health status. The addition of perceived safety changed the magnitude of the statistically significant regression coefficients by $8-28 \%$ (see table 4). For women, the rates of violent crime and crime occurring at night remained significantly associated with physical health after controlling for perception of neighbourhood as unsafe.

\section{Association between perceived crime and physical health status}

Both men and women perceiving their neighbourhood as unsafe for walking at night had lower predicted physical health index: men perceiving their neighbourhood as unsafe versus safe had a predicted difference of 1.3 units on the physical health index, and women had a predicted difference of 0.9 units (table 5). These associations remained statistically significant and similar in magnitude after controlling for recorded crime rates.

\section{DISCUSSION}

For this population of adults living in New Zealand, we observed robust associations between objectively

Table 4 Associations between recorded crime rates and self-reported physical health status among men and women in New Zealand (2010-2011)

\begin{tabular}{|c|c|c|c|c|}
\hline & Overall $\beta(95 \% \mathrm{Cl})$ & Men $\beta(95 \% \mathrm{Cl})$ & Women $\beta$ (95\% Cl) & $\begin{array}{l}\text { Gender } \\
\text { interaction } p \text { value }\end{array}$ \\
\hline Total crime & $-0.09(-0.20$ to 0.01$)$ & $-0.04(-0.18$ to 0.09$)$ & $-0.15(-0.29$ to -0.01$)$ & 0.22 \\
\hline With perceived safety & $-0.08(-0.18$ to 0.03$)$ & $-0.02(-0.16$ to 0.11$)$ & $-0.13(-0.27$ to 0.00$)$ & \\
\hline Violent crime & $-0.18(-0.34$ to -0.01$)$ & $-0.04(-0.27$ to 0.20$)$ & $-0.32(-0.55$ to -0.10$)$ & 0.08 \\
\hline With perceived safety & $-0.13(-0.30$ to 0.03$)$ & $0.02(-0.22$ to 0.25$)$ & $-0.29(-0.51$ to -0.06$)$ & \\
\hline Property crime & $-0.13(-0.40$ to 0.13$)$ & $0.07(-0.25$ to 0.38$)$ & $-0.33(-0.76$ to 0.09$)$ & 0.13 \\
\hline With perceived safety & $-0.08(-0.34$ to 0.19$)$ & $0.12(-0.19$ to 0.44$)$ & $-0.28(-0.71$ to 0.15$)$ & \\
\hline Dishonesty crime & $-0.10(-0.29$ to 0.09$)$ & $0.05(-0.20$ to 0.30$)$ & $-0.27(-0.52$ to -0.01$)$ & 0.06 \\
\hline With perceived safety & $-0.08(-0.27$ to 0.10$)$ & $0.06(-0.19$ to 0.30$)$ & $-0.24(-0.49$ to 0.01$)$ & \\
\hline Drug and antisocial crime & 0.17 (0.00 to 0.33$)$ & $0.24(0.03$ to 0.44$)$ & $0.10(-0.17$ to 0.37$)$ & 0.38 \\
\hline With perceived safety & 0.19 (0.03 to 0.35$)$ & 0.26 (0.06 to 0.47$)$ & $0.12(-0.14$ to 0.39$)$ & \\
\hline Crime with a weapon & $0.29(-0.37$ to 0.95$)$ & $0.58(-0.24$ to 1.39$)$ & $-0.04(-0.97$ to 0.89$)$ & 0.28 \\
\hline With perceived safety & $0.42(-0.24$ to 1.18$)$ & $0.71(-0.09$ to 1.52$)$ & $0.09(-0.84$ to 1.02$)$ & \\
\hline Crime at night & $-0.11(-0.26$ to 0.03$)$ & $0.04(-0.14$ to 0.23$)$ & $-0.29(-0.51$ to -0.07$)$ & 0.01 \\
\hline With perceived safety & $-0.09(-0.23$ to 0.06$)$ & 0.08 (-0.11 to 0.27$)$ & $-0.26(-0.48$ to -0.04$)$ & \\
\hline
\end{tabular}


Table 5 Associations between perception of safety and self-reported physical health status, controlling for recorded crime among men and women living in New Zealand (2010-2011)

\begin{tabular}{llll}
\hline & Overall $\boldsymbol{\beta}(95 \% \mathbf{C l})$ & Men $\boldsymbol{\beta}(95 \% \mathbf{C I})$ & Women $\boldsymbol{\beta}(95 \% \mathbf{C l})$ \\
\hline Neighbourhood perceived as unsafe & $-1.00(-1.51$ to -0.49$)$ & $-1.31(-2.18$ to -0.44$)$ & $-0.86(-1.49$ to -0.23$)$ \\
$\quad$ With total crime & $-0.97(-1.48$ to -0.45$)$ & $-1.30(-2.17$ to -0.43$)$ & $-0.80(-1.43$ to -0.17$)$ \\
With violent crime & $-0.95(-1.46$ to -0.43$)$ & $-1.32(-2.19$ to -0.44$)$ & $-0.77(-1.40$ to -0.13$)$ \\
With property crime & $-0.99(-1.50$ to -0.47$)$ & $-1.33(-2.20$ to -0.46$)$ & $-0.82(-1.45$ to -0.18$)$ \\
With dishonesty crime & $-0.99(-1.50$ to -0.48$)$ & $-1.31(-2.18$ to -0.44$)$ & $-0.82(-1.46$ to -0.19$)$ \\
With drug and antisocial crime & $-1.03(-1.54$ to -0.52$)$ & $-1.35(-2.22$ to -0.48$)$ & $-0.88(-1.50$ to -0.25$)$ \\
With crime with a weapon & $-1.03(-1.54$ to -0.51$)$ & $-1.36(-2.23$ to -0.48$)$ & $-0.87(-1.50$ to -0.24$)$ \\
With crime at night & $-0.97(-1.48$ to -0.46$)$ & $-1.34(-2.22$ to -0.47$)$ & $-0.78(-1.41$ to -0.15$)$ \\
\hline
\end{tabular}

Coefficients and $95 \%$ Cls from cluster robust linear models predicting the physical health index are shown, and coefficients can be interpreted as the predicted difference in physical health status (as measured by the SF-12 transformed physical component score) for comparing those reporting their neighbourhood as unsafe for walking at night versus safe for walking at night; covariates include age, ethnicity, place of birth, education, employment, income and smoking status; crime rates were added one at a time to adjusted models and the coefficients for perceiving neighbourhood as unsafe are shown before and after adjustment for each of these crime rates; italic face is used to indicate statistical significance $(p<0.05)$.

recorded crime rates and perceived neighbourhood safety, and between perceived neighbourhood safety and physical health. However, there was some evidence of effect modification by gender in the association between objectively recorded crime rates and physical health. Moreover, the category of crime rates most strongly associated with perceived safety (crime with a weapon) was not among the categories most strongly associated with physical health (violent crime and crime at night). The observed patterns were somewhat supportive of the hypothesised role of perceived safety as a mediator between officially recorded crime rates and physical health among women. However, the observed patterns indicate potential heterogeneity by crime type and gender.

An understanding of the several causal pathways through which crime may affect health can help explain these separate associations, and differences across categories of crime. It appears that for women, violent crime and crimes occurring at night were negatively associated with health status even after controlling for any indirect association through perceived safety. Yet, the magnitude of association between perceived neighbourhood safety and physical health showed a trend to be larger for men than women. These findings highlight separate associations of officially recorded crime versus perceived safety hazards on health, and that these associations may differ by gender. Our results corroborate other studies ${ }^{12} 1432$ that have found independent associations for between the perception of safety and officially recorded crime with health status or health-related behaviour. ${ }^{11}{ }^{14}$ Perceived safety-instead of merely being a reflection of recorded crime-is an independent construct that can be influenced by a variety of environmental cues such as the physical features of public spaces, lighting levels, media stories and social incivilities. ${ }^{9}$ Future longitudinal research should consider how shortterm fluctuations and long-term trends in crime rates and other neighbourhood shifts alter individuals' reported perceptions of neighbourhood safety. While perceived safety may, in part, mediate the association between recorded crime and physical health status among women in our study, the association of perceived crime with adverse physical health was notable and statistically significant among men, even though recorded crime rates were not associated with physical health for these same men.

It is worth noting that when effect modification by gender has been explored in previous studies of crime or safety as predictors of physical health, the patterns have not always been consistent with our findings. For example, others have reported a stronger association between perceived safety and health status for women, ${ }^{10}$ whereas in this study we found a trend in the opposite direction, though the effect modification was not statistically significant. Some of the literature on perceived safety and physical activity has pointed to stronger associations for men $^{33}$ or failed to detect an association among women. ${ }^{16} 3435$ One potential explanation for the stronger associations between perceived safety and physical activity and physical health among men involve reverse causation, with physically healthy men more likely to perceive themselves as being safe from crime. The inconsistent evidence for the association of perceived crime on health status by gender underscores the importance of using officially recorded and perceived crime measures and presenting gender stratified results even when the pattern of effect modification seems contrary to current assumptions.

\section{Strengths and limitations}

Key strengths of this study are the use of geographically linked national data, and the availability of multiple officially recorded crime rates by category as well as a survey question on perceived neighbourhood safety. The SF-12 instrument used for outcome assessment has been validated $^{25}$ and recommended as a population health measure. $^{36}$ 
However, the cross-sectional and observational study designs limit our ability to eliminate non-causal explanations such as reverse causation and unmeasured confounding. Physical health status was self-reported and this could result in misclassification. Missing data were also an important limitation. In particular, the large number of participants who selected 'Not applicable', 'Don't know' or 'Refused' in response to the question on perceived safety $(\mathrm{N}=1092)$ may have included those who already avoided walking home at night due to safety concerns or health limitations, and this could lead to a biased estimate of the associations among crime rates, perceived safety and health status. Misclassification or reasons for missing data could also differ by gender, potentially distorting the observed pattern of effect modification. The measure of perceived safety too did not explicitly state the source for concern with safety and some participants may be considering factors such as traffic hazards instead of crime. Last, crime rates in New Zealand are lower than in many other countries (eg, in 2000, the New Zealand violent crime rates were 132.6 per 100000 compared to 506.1 per 100000 population in the $\mathrm{USA}^{37}$ ); this and other unique sociocultural factors may change how its neighbourhoods function and influence health, limiting the generalisability of our results.

\section{CONCLUSION}

In conclusion, complex patterns of association were observed linking crime rates to physical health among men and women in New Zealand. Future studies should continue to explore differences by crime category and by gender, and across the multiple pathways that may link crime rates to physical health status. Usage of officially recorded crime and perceived safety measures is important to tease apart the differences in what they reflect and how they may influence health differently for men and women. Perceived neighbourhood safety in particular appears to be a robust predictor of physical health independent of officially recorded crime rates, and potentially modifiable neighbourhood characteristics affecting perceived safety warrant further investigation.

Acknowledgements The authors would like to acknowledge the support of New Zealand Police who provided crime data for this work; and to Statistics New Zealand who provided access to data from the General Social Survey.

Contributors All authors critically reviewed manuscript drafts and approved the submission. GSL, ALP and GB conceived the project. GB prepared the official crime rate data for linkage to the New Zealand General Social Survey (NZGSS). ALP conducted analyses in the secure data lab, with syntax and input from GSL. CEG created tables from the output files and drafted the initial manuscript. GSL revised and integrated comments on the final tables and text.

Funding The Christchurch City Council initiated the research and the Ministry of Justice Crime Prevention Unit was responsible the provision of funding, which allowed the project to start smoothly. The National Institute for Child Health and Human Development (K01HD067390) provided financial support for the first author.
Disclaimer Access to the data used in this study was provided by Statistics New Zealand under conditions designed to uphold the security and confidentiality provisions of the Statistics Act 1975. The results presented in this study are the work of the authors, not Statistics New Zealand.

\section{Competing interests None.}

Ethics approval The linkage and statistical analyses of microdata for this manuscript took place at a Statistics New Zealand Data Lab in Wellington, NZ, and the proposal to do so was approved by the New Zealand Police and Statistics New Zealand.

Provenance and peer review Not commissioned; externally peer reviewed.

Data sharing statement Details on data availability may be found at http:// www.stats.govt.nz.

Open Access This is an Open Access article distributed in accordance with the Creative Commons Attribution Non Commercial (CC BY-NC 3.0) license, which permits others to distribute, remix, adapt, build upon this work noncommercially, and license their derivative works on different terms, provided the original work is properly cited and the use is non-commercial. See: http:// creativecommons.org/licenses/by-nc/3.0/

\section{REFERENCES}

1. Diez Roux AV, Mair C. Neighborhoods and health. Ann N Y Acad Sci 2010;1186:125-45.

2. Riva M, Gauvin L, Tracie TA, et al. Toward the next generation of research into small area effects on health: a synthesis of multilevel investigations published since July 1998. J Epidemiol Community Health 2007;61:853-61.

3. Pickett KE, Pearl M. Multilevel analyses of neighbourhood socioeconomic context and health outcomes: a critical review. J Epidemiol Community Health 2001;55:111-22.

4. Ross CE, Mirowsky J. Neighborhood disadvantage, disorder, and health. J Health Soc Behav 2001;42:258-76.

5. Chaix B, Lindstrom M, Rosvall M, et al. Neighbourhood social interactions and risk of acute myocardial infarction. $J$ Epidemiol Community Health 2008;62:62-8.

6. Sundquist $\mathrm{K}$, Theobald $\mathrm{H}$, Yang $\mathrm{M}$, et al. Neighborhood violent crime and unemployment increase the risk of coronary heart disease: a multilevel study in an urban setting. Soc Sci Med 2006;62:2061-71.

7. Ellen IG, Mijanovich T, Dillman KN. Neighborhood effects on health: exploring the links and assessing the evidence. J Urban Aff 2001;23:391-408.

8. Stafford M, Chandola T, Marmot M. Association between fear of crime and mental health and physical functioning. Am J Public Health 2007;97:2076-81.

9. Loukaitou-Sideris A, Eck JE. Crime prevention and active living. Am $J$ Health Promot 2007;21(Suppl 4):380-9, iii.

10. Foster S, Giles-Corti B. The built environment, neighborhood crime and constrained physical activity: an exploration of inconsistent findings. Prev Med 2008;47:241-51.

11. Mason P, Kearns A, Livingston M. "Safe Going": the influence of crime rates and perceived crime and safety on walking in deprived neighbourhoods. Soc Sci Med 2013;91:15-24.

12. Piro FN, Noss O, Claussen B. Physical activity among elderly people in a city population: the influence of neighbourhood level violence and self perceived safety. J Epidemiol Community Health 2006;60:626-32.

13. Shareck M, Ellaway A. Neighbourhood crime and smoking: the role of objective and perceived crime measures. BMC Public Health 2011;11:930.

14. Evenson KR, Block R, Diez Roux AV, et al. Associations of adult physical activity with perceived safety and police-recorded crime: the multi-ethnic study of atherosclerosis. Int J Behav Nutr Phys Act 2012;9:146.

15. Johnson SL, Solomon BS, Shields WC, et al. Neighborhood violence and its association with mothers' health: assessing the relative importance of perceived safety and exposure to violence. $J$ Urban Health 2009;86:538-50.

16. Blacksher E, Lovasi GS. Place-focused physical activity research, human agency, and social justice in public health: taking agency seriously in studies of the built environment. Health Place 2012;18:172-9.

17. Lovasi GS, Schwartz-Soicher O, Neckerman KM, et al. Aesthetic amenities and safety hazards associated with walking and bicycling 
for transportation in New York City. Ann Behav Med 2013; 45(Suppl 1):S76-85.

18. Ding D, Adams MA, Sallis JF, et al. Perceived neighborhood environment and physical activity in 11 countries: do associations differ by country? Int J Behav Nutr Phys Act 2013;10:57.

19. Suminski RR, Poston WS, Petosa RL, et al. Features of the neighborhood environment and walking by U.S. adults. Am J Prev Med 2005;28:149-55.

20. Shenassa ED, Liebhaber A, Ezeamama A. Perceived safety of area of residence and exercise: a pan-European study. Am J Epidemiol 2006;163:1012-17.

21. Reid LW, Konrad MK. The gender gap in fear: assessing the interactive effects of gender and perceived risk on fear of crime. Sociol Spectr 2004:399-425.

22. Stafford M, Cummins S, Macintyre S, et al. Gender differences in the associations between health and neighbourhood environment. Soc Sci Med 2005;60:1681-92.

23. Statistics New Zealand. New Zealand General Social Survey: 2010, 2011. http://www.stats.govt.nz/nzgss (accessed 1 Feb 2013)

24. Ware JE, Sherbourne CD. The MOS 36-item short form health survey (SF-36). I. Conceptual framework and item selection. Med Care 1992;30:473-83.

25. Ware JE, Kosinski M, Keller SD. A 12-item short-form health survey. Construction of scales and preliminary tests of reliability and validity. Med Care 1996;34:220-33.

26. Frieling MA, Davis WR, Chiang G. The SF-36v2 and SF-12v2 health surveys in New Zealand: norms, scoring coefficients and cross-country comparisons. Aust N Z J Public Health 2013;37:24-31.

27. Breetzke GD, Pearson AL. The fear factor: examining the spatial variability of recorded crime on the fear of crime. Appl Geography 2014;46:45-52.
28. Foster C, Hillsdon M, Thorogood M. Environmental perceptions and walking in English adults. J Epidemiol Community Health 2004; 58:924-8.

29. Ball K, Timperio A, Salmon J, et al. Personal, social and environmental determinants of educational inequalities in walking: a multilevel study. J Epidemiol Community Health 2007;61:108-14.

30. Giles-Corti B, Donovan RJ. Socioeconomic status differences in recreational physical activity levels and real and perceived access to a supportive physical environment. Prev Med 2002;35:601-11.

31. Argeseanu Cunningham S, Ruben JD, Narayan KM. Health of foreign-born people in the United States: a review. Health Place 2008;14:623-35.

32. McGinn AP, Evenson KR, Herring AH, et al. The association of perceived and objectively measured crime with physical activity: a cross-sectional analysis. J Phys Act Health 2008;5:117-31.

33. De Bourdeaudhuij I, Sallis JF, Saelens BE. Environmental correlates of physical activity in a sample of Belgian adults. Am J Health Promot 2003;18:83-92.

34. Rohm Young D, Voorhees CC. Personal, social, and environmental correlates of physical activity in urban African-American women. $\mathrm{Am}$ J Prev Med 2003;25(3 Suppl 1):38-44.

35. Voorhees CC, Rohm Young D. Personal, social, and physical environmental correlates of physical activity levels in urban Latinas. Am J Prev Med 2003;25(3 Suppl 1):61-8.

36. Burdine JN, Felix MR, Abel AL, et al. The SF-12 as a population health measure: an exploratory examination of potential for application. Health Serv Res 2000;35:885-904.

37. Segessenmann T. International comparisons of recorded violent crime rates for 2000. In: Research and evaluation unit, Ministry of Justice, New Zealand, 2002. http://www.justice.govt.nz/publications/ crime (accessed 1 Feb 2013). 